\title{
Irradiação ionizante em pós-colheita de atemoia cultivar 'Thompson'
}

\author{
Geraldo Henrique Martins Vieira
}

Centro Paula Souza. E-mail: ghmv01@gmail.com

\section{Resumo}

O estudo da irradiação ionizante com Cobalto $60\left({ }^{60} \mathrm{Co}\right)$, neste experimento, teve por objetivo avaliar sua influência em parâmetros físicos de pós-colheita para atemoia cv. 'Thompson', os quais se relacionam ao processo de amadurecimento da fruta. A irradiação foi realizada no Centro de Tecnologia das Radiações CTR IPEN/CNEN - SP, situado na cidade universitária USP (Universidade de São Paulo) no irradiador multipropósito do tipo compacto onde se utiliza raios gama. As atemoias foram irradiadas com as seguintes doses de cobalto $60\left({ }^{60} \mathrm{Co}\right): T_{0}$ Sem irradiação (controle), $T_{1=0,2 k G y,} T_{2}=0,4 k G y, T_{3}=0,6 k G y, T_{4}=0,8 k G y$, $\mathrm{T}_{5}=1,0 \mathrm{kGy}$ e $\mathrm{T}_{6=} 1,2 \mathrm{kGy}$ sendo posteriormente embaladas em bandejas de poliestireno expandido (2 frutas/bandeja) e selados com filmes de policloreto de vinila $0,020 \mathrm{~mm}$; exceção feita ao tratamento controle o qual não recebeu irradiação; para cada parâmetro de análise houve três repetições com duas frutas por repetição. As frutas em estudo foram armazenadas em câmara fria nas condições de $15 \pm 0,2 \circ \mathrm{C} e$ $90 \pm 2 \%$ de UR. Em todas as doses de irradiação, foram realizadas as análises de: perda de massa fresca, sólidos solúveis (SS), acidez titulável (AT), pH, ácido ascórbico (AA), açúcares redutores, taxa respiratória. As análises foram analisadas a cada três dias $(0,3,6,9,12,15$ e 18) dias de armazenamento. 0 experimento foi conduzido em delineamento inteiramente casualizado (D.I.C.), em esquema fatorial (tratamento $x$ armazenamento), compostos pelas sete doses de irradiação gama e sete tempos de armazenamento. Os resultados foram submetidos à análise de variância e as médias comparadas pelo teste de Tukey ao nível de $5 \%$ de probabilidade e fez-se regressão, para as análises no período de armazenamento. Este experimento pode concluir que as doses de 1,0kGy e 1,2kGy demonstram maior controle da respiração, na atemoia, até o 9 dia; três dias a mais que o tratamento controle, os demais parâmetros analisados não demonstraram interferência no aumento de vida pós-colheita da atemoia cv 'Thompson'.

Palavras-chave: Análise física; Annona x atemoya Mabb; armazenamento.

\section{Ionizing irradiation in postharvest in the atemoia cultivar 'Thompson'}

\section{ABSTRAT}

The study of ionizing irradiation with Cobalt $60(60 \mathrm{Co})$, in this experiment, aimed to evaluate its influence on postharvest physical parameters for atemoia cv. 'Thompson', which are related to the fruit ripening process. The irradiation was carried out at the Radiation Technology Center - CTR IPEN / CNEN - SP, located in the university city USP (University of São Paulo) in the compact multi-purpose radiator where gamma rays are used. Atemias were irradiated with the following doses of cobalt 60 (60Co): TO = No irradiation (control), $\mathrm{T} 1=0.2 \mathrm{kGy}, \mathrm{T} 2=0.4 \mathrm{kGy}, \mathrm{T} 3=0.6 \mathrm{kGy}, \mathrm{T} 4=0.8 \mathrm{kGy}, \mathrm{T} 5=1,0 \mathrm{kGy}$ and $\mathrm{T} 6=1,2 \mathrm{kGy}$ and then packed in expanded polystyrene trays ( 2 fruits / tray) and sealed with $0.020 \mathrm{~mm}$ polyvinyl chloride films; exception made to the control treatment which did not receive irradiation; for each analysis parameter there were three repetitions with two fruits per repetition. The fruits under study were stored in a cold chamber at 15 $\pm 0.2^{\circ} \mathrm{C}$ and $90 \pm 2 \% \mathrm{RH}$. In all irradiation doses, the following analyzes were carried out: loss of fresh mass, soluble solids (SS), titratable acidity (AT), $\mathrm{pH}$, ascorbic acid (AA), reducing sugars, respiratory rate. The analyzes were analyzed every three days $(0,3,6,9,12,15$ and 18$)$ days of storage. The experiment was conducted in a completely randomized design (D.I.C.), in a factorial scheme (treatment $x$ storage), composed of seven doses of gamma irradiation and seven storage times. The results were subjected to analysis of variance and the means compared by Tukey's test at the level of $5 \%$ probability and regression was performed for the analyzes in the storage period. This experiment can conclude that the doses of 
$1.0 \mathrm{kGy}$ and $1.2 \mathrm{kGy}$ demonstrate greater control of breathing, in atemoia, until the 9th day; three days more than the control treatment, the other parameters analyzed did not show any interference in the increase in postharvest life of the atemous cv 'Thompson'.

Keywords: Physical analysis; Annona x atemoya Mabb.; storage.

\section{Introdução}

A atemoia pertence à família das anonáceas, que possui 128 gêneros e 2.300 espécies diferentes; sua diversidade no Brasil é caracterizada por apresentar 29 gêneros, com aproximadamente 385 espécies, sendo 128 endêmicas (JUDD, 2009; MARTINELLI, 2013).

$A$ atemoia (Annona $x$ atemoya Mabb) é um híbrido, resultante do cruzamento de uma espécie originária da Anonna cherimola Mill. (cherimóia), a qual ocorre espontaneamente nas regiões andinas do Chile, Peru, Bolívia, Equador e em locais de clima ameno e da $A$. squamosa $\mathrm{L}$. (fruta do conde, ata ou pinha que é originária das terras baixas da América Central (BONAVENTURE, 1999; TOKUNAGA, 2000).

A hibridação que deu origem a atemoia, ocorreu nos EUA no Estado da Flórida no ano de 1908, no "United States Department of Agriculture's Subtropical Laboratory", localizado em Miami (MORTON, 1987).

Existem várias cultivares da referida fruta, a exemplo de: 'Thompson', 'Gefner', 'African Pride' e 'PR3', este trabalho utilizou-se da cultivar Thompson, por ser a os agricultores regionais cultivam.

O crescimento da produção da atemoia no Brasil da ênfase a importância da fruticultura no país, sendo que a atemoia correspondeu no ano de 2016 a 39.305 .097 toneladas em uma área de 1.991.445 ha (CONAB, 2017); sendo que - Estado de São Paulo é o maior produtor nacional com $43,8 \%$ da produção, seguido por Minas Gerais, Paraná e Bahia; cada estado com aproximadamente $18 \%$ da produção. A estes dados soma-se também a expressiva contribuição na geração de empregos, pois a atividade necessita em média, três empregos por hectare.

A relevância de importância econômica da fruticultura brasileira, também demonstra que as perdas do pós-colheita chegam a $30 \%$ da produção; perdas estas, ligadas a itens da cadeia produtiva como o transporte, embalagem, armazenamento e processamento; Chitarra e Chitarra (2005) salienta que durante o processo de amadurecimento as frutas estão sujeitas a uma grande quantidade de processos degradativos, sendo que o uso da irradiação ionizante é uma das tecnologias passíveis de uso no pós-colheita de frutas.

O objetivo do uso desta tecnologia neste experimento, encontra relevância nas citações de Evangelista (2008), Chitarra e Chitarra (2005), O'Beirne (1989) e Fellows (2006), os quais relatam o uso desta tecnologia como opção, para se conservar o alimento, protegendo-o contra agentes de deterioração; sendo que a referida tecnologia tem por finalidade esterilizar, ou diminuir os insetos infectantes de frutas e/ou vegetais, não provocando aumento de calor, e possibilitando retardo no ciclo de maturação sem alterar características sensoriais como: exaltação de aroma, sabor e cor.

No Brasil, a regulamentação do uso da irradiação ionizante em alimentos está amparada pelo Ministério da Saúde pelo Decreto $\mathrm{n}^{\circ} 72.718$, de 29 de agosto de 1973, a Lei $\mathrm{n}^{\circ}$ 7.394 , de 29 de outubro de 1985, e a Resolução RDC $n^{\circ} 21$, de 26 de janeiro de 2001 (GAVA, 2009).

A aceitação do uso da tecnologia oriunda da radioatividade, nos alimentos tem sido discutida pela Joint FAO/IAEA/WHO Expert Comittee on the Wholesomenes of Irradiated Food (JECFI), que concluiu como dose média máxima $10 \mathrm{kGy}$, para o ser humano sem que a mesma represente perigo toxicológico e ou problema microbiológico ou nutricional especial em alimentos (WHO, 1977, 1981); (FELLOWS, 2006).

Entre as irradiações ionizantes, estão a alfa, beta, gama, raios $X$ e ultravioleta; o que as diferencia é sua forma de atuação. $A$ irradiação alfa não penetra uma folha de papel, a irradiação beta pode ser interrompida por uma folha de alumínio, e a irradiação gama, usada neste trabalho, é altamente penetrante e consegue ultrapassar um bloco de chumbo, não muito espesso Gava (2009); sendo que a fonte de raios gama utilizada neste experimento, cobalto 60 , caracteriza-se por ser o de maior produção 
energética, sendo um isótopo artificial, obtido da irradiação do cobalto natural (EVANGELISTA, 2008).

Atualmente, prefere-se fazer a classificação de acordo com a dose empregada, dessa forma, consideram-se tratamentos como dose baixa (até $1 \mathrm{kGy}$ ), com dose média (de 1 a $10 \mathrm{kGy}$ ) e com dose alta (de 10 a 50kGy), sendo que o termo radurização consiste em aplicar doses entre 0,4 e $10 \mathrm{kGy}$ de radiação ionizante reduzem sensivelmente a carga microbiana qual pode influenciar na diminuição da vida útil do alimento.

O objetivo deste trabalho foi avaliar a influência da irradiação ionizante, com cobalto 60, em frutos de atemoia cv 'Thompson' para parâmetros físico/químicos relacionados ao amadurecimento da fruta no decorrer de 18 dias de armazenamento.

\section{Material e métodos}

As atemoias cv. 'Thompson', foram adquiridas em uma propriedade rural, localizada em Campos de Holambra, distrito da cidade de Paranapanema SP; estando o pomar com idade de cinco anos e localizado geograficamente nas coordenadas: latitude 220 37' 59" sul e longitude 470 03' 20" oeste; a 670 metros de altitude.

A colheita das atemoias ocorreu no mês de maio, ao entardecer do dia anterior ao início das análises. O transporte destas fora feito estando as frutas previamente selecionadas, classificadas seguindo o padrão 12, (doze frutas por caixa padrão de venda); sendo que a caixa padrão de venda comporta de 4 a $4,5 \mathrm{Kg}$ de fruta, o que determina a referência numérica citada. As frutas transportadas foram acondicionadas em caixas plásticas medindo 36 $\mathrm{cm}$ de largura $\times 55 \mathrm{~cm}$ de comprimento e $30 \mathrm{~cm}$ de profundidade e protegidas em camadas por papel Kraft.

A metodologia utilizada, para caracterizar os tratamentos e repetições foi o de acondicionar as atemoias em bandejas de poliestireno expandido ( 2 frutas/bandeja) e selados com filme de policloreto de vinila $0,020 \mathrm{~mm}$.

As atemoias foram então transportadas ao IPEN - Instituto de Pesquisa Energéticas e Nucleares, localizado no Centro de Tecnologia das Radiações - CTR IPEN/CNEN - SP, situado na cidade universitária USP (Universidade de São Paulo), para serem submetidas as doses de irradiação com cobalto $60\left({ }^{60} \mathrm{CO}\right)$ no irradiador multipropósito do tipo compacto onde se utiliza o raio gama.

Este transporte foi realizado no dia posterior a colheita sendo que as atemoias $\mathrm{cv}$. "Thompson" foram tratadas nas doses: $\mathrm{T}_{0=} \mathrm{Sem}$

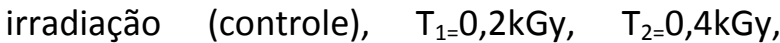

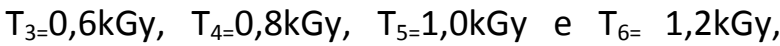
onde para cada tratamento foi atribuída três repetições com duas frutas por repetição; com posterior armazenamento em câmara fria, a $15 \pm$ $0,2 \circ$ C e $90 \pm 2 \%$ de UR por 18 dias;

$\mathrm{Na}$ sequência, as atemoias foram encaminhadas ao Laboratório de pós-colheita da Faculdade de Ciências Agronômicas - FCA "Júlio de Mesquita Filho" UNESP - Câmpus de Botucatu SP, onde foram armazenadas em câmara fria a $15 \pm 0,2 \circ \mathrm{C}$ e $90 \pm 2 \%$ de UR por 18 dias.

O delineamento foi 0 inteiramente casualizado (DIC) em esquema fatorial $7 \times 7$, com três repetições. Os tratamentos foram doses de

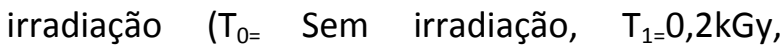
$\mathrm{T}_{2}=0,4 \mathrm{kGy}, \mathrm{T}_{3}=0,6 \mathrm{kGy}, \mathrm{T}_{4=0} 0,8 \mathrm{kG}, \mathrm{T}_{5}=1,0 \mathrm{kGy}$ e $\mathrm{T}_{6=}$ $1,2 \mathrm{kGy}$ ) combinadas com período de armazenamento $(0,3,6,9,12,15$ e 18 dias $)$. Os dados foram submetidos à análise de variância pelo teste $\mathrm{F}$ ao nível de $95 \%$ de probabilidade. As médias foram comparadas por meio do teste de Tukey e fez-se regressão para avaliações nos tempos de armazenamento; o programa estatístico utilizado foi o Sisvar (FERREIRA, 2010).

\section{Perda de Massa}

A perda de massa foi avaliada utilizandose balança semi-analítica (MARTE ${ }^{\circ}$, modelo BL $3200 \mathrm{H}$ - carga máxima de $2000 \mathrm{~g}$ e precisão de $0,01 \mathrm{~g}$ ). As amostras foram pesadas no início do experimento e a cada 3 dias até o total de 18 dias, permitindo o cálculo da perda de massa fresca expressa em porcentagem.

\section{Potencial hidrogeniônico (pH)}

A determinação do potencial hidrogeniônico $(\mathrm{pH})$ foi mensurada da polpa triturada dos frutos utilizando-se um pHmetro (Digital DMPH-2), segundo a metodologia da AOAC (2019),

\section{Acidez titulável (AT)}

A acidez titulável foi obtida por meio da titulação de $5 \mathrm{~g}$ de polpa homogeneizada e diluída em $100 \mathrm{~mL}$ de água destilada, com solução padronizada de hidróxido de sódio $(\mathrm{NaOH})$ a $0,1 \mathrm{Mol} \mathrm{L}^{-1}$, tendo como indicador a 
fenolftaleína, que se dá quando o pHmetro atinge 8,1, conforme recomendação do Instituto Adolfo Lutz (IAL, 2008). Os resultados foram expressos em gramas de ácido cítrico por $100 \mathrm{~g}$ de polpa.

\section{Sólidos solúveis (SS)}

Os sólidos solúveis foram determinados por refratometria, em refratômetro digital (Palette PR - 32, ATAGO), com compensação de temperatura automática, segundo a AOAC (1992) e os resultados foram expressos em ${ }^{\circ}$ Brix.

\section{Resultados e Discussão}

Os dados obtidos com a atividade respiratória das atemoias, demonstrou que 0 tratamento com dose de 1,2kGy, foi o único que manteve taxa respiratória reduzida até o 60 dia de armazenamento; sendo este valor $33,9 \%$ menor que a maior taxa encontrada no período, a qual foi observada no tratamento de $0,8 \mathrm{kGy}$, dados estes apresentados na (Figura 1). A respiração é um processo bioquímico que as células realização com o objetivo de produzir energia na forma de ATP e $\mathrm{NADH}+\mathrm{H}^{+}$na glicólise e no ciclo de Krebs ou de NADPH + H+ e açúcares de 4,5 e 7 carbonos na rota das pentoses (CALBO, 2007). Durante a fase de amadurecimento até o final do desenvolvimento ou maturação as frutas apresentam um aumento na taxa de respiração; este processo classifica a fruta em climatéria (CHITARRA; CHITARRA, 2005). A redução da respiração pode ser proveniente do controle de microrganismos os quais podem causar deterioração do fruto, acelerando seu processo de amadurecimento; esta afirmação corrobora com Ventura et al. (2010) caracteriza que os principais alvos da radiação gama no controle de microrganismo, sendo os ácidos nucleicos e lipídeos da membrana; sendo a energia da radiação gama suficiente para atuar no DNA dos microrganismos, impossibilitando sua reprodução. Tezotto et al. (2014), explica a ação da radiação gama como atuante no controle de microrganismos através de danos ao seu DNA. As lesões letais ao DNA são espalhadas através das células durante o processo de divisão celular, e as que são incapazes de reparar tais danos morrem; Mendonça (2016) estudando o uso de radiação gama em caqui cv 'Kioto', conclui que doses mais baixas (0,3 e 0,6 kGy) mostraram-se adequadas prolongando a conservação da fruta por 21 dias; esses dados corroboram com Neves (2009) que estudando a aplicação da radiação gama em nectarina cv. 'Sunred' observou que a dose de 0,4 kGy possibilitou a conservação da fruta por 28 dias; essas afirmações caracterizam o uso da radiação ionizante, como uma técnica viável na conservação da fruta no pós-colheita. Não foi encontrado, na literatura, dados sobre o uso da radiação gama em atemoias. 
Figura 1. Atividade respiratória ( $\mathrm{mL}$ de $\mathrm{CO} 2 \mathrm{Kg}$ de fruta-1 hora-1) em função das doses de irradiação (kGy) em atemoia cv. 'Thompson' acondicionadas em bandejas de poliestireno expandido e policloreto de vinila e armazenadas a $15 \pm 0,2 \circ \mathrm{O}$ e $90 \pm 2 \%$ de UR por 18 dias. Botucatu SP

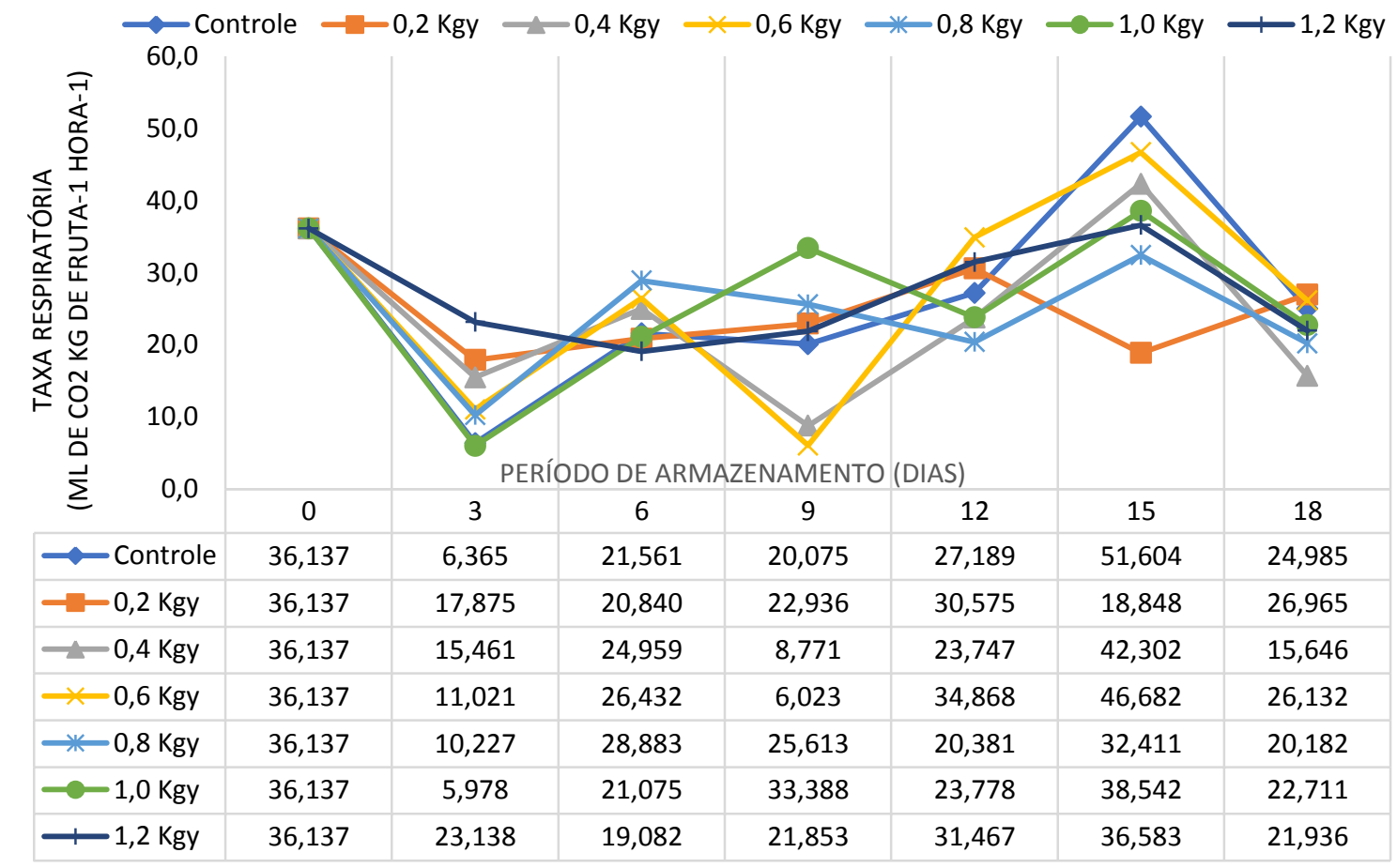

\section{Sólidos solúveis (SS) em atemoia irradiada}

A análise da Figura 2, possibilita a observação dos resultados referentes as médias obtidas com as doses de irradiação durante o período de armazenamento, para sólidos solúveis. Os frutos irradiados com $1,2 \mathrm{kGy}$ apresentaram média de $16,75^{\circ}$ Brix, resultado $12,4 \%$ menor que o valor encontrado no tratamento controle. Este resultado é explicado por Chitarra e Chitarra (2005), que relatam o aumento dos teores de sólidos solúveis, em frutas climatérias, durante o amadurecimento em decorrência da degradação de polissacarídeos. Esta degradação ocorre na atmosfera interna das células, visto que são as concentrações de $\mathrm{CO}_{2}$, $\mathrm{O}_{2}$, etileno e outros compostos voláteis que determinam as respostas de desenvolvimento e senescência das frutas (CALBO, 2007). Esta afirmação sugeri, que a irradiação não interferiu na respiração, mas possivelmente no controle de microrganismos, que poderiam afetar a mesma, acelerando assim a respiração e consequentemente $\mathrm{o}$ aumento dos sólidos solúveis. Os dados obtidos neste experimento divergem de Lundgren (2017) a qual encontrou valores de sólidos solúveis em atemoia cv. 'Thompson' de 32 'Brix para todos os tratamentos realizados com 1-MCP (1Metilciclopropeno), estando as frutas armazenadas sob refrigeração $(15 \pm 1$ 으 e $90 \pm$ $5 \%$ de UR) durante 18 dias; esta informação corrobora com Silva (2011) que estudando atributos de qualidade da atemoia cv. 'Gefner' colhida em dois estádios de maturação ("de vez" e maduros) obteve média nos sólidos solúveis de $30,47^{\circ}$ Brix. 
Figura 2. Teores médios de sólidos solúveis ('Brix) em função das doses de irradiação (kGy) em atemoia cv. 'Thompson' acondicionadas em bandejas de poliestireno expandido policloreto de vinila e armazenadas a $15 \pm 0,2 \circ \mathrm{C}$ e $90 \pm 2 \%$ de UR por 18 dias. Botucatu, SP.

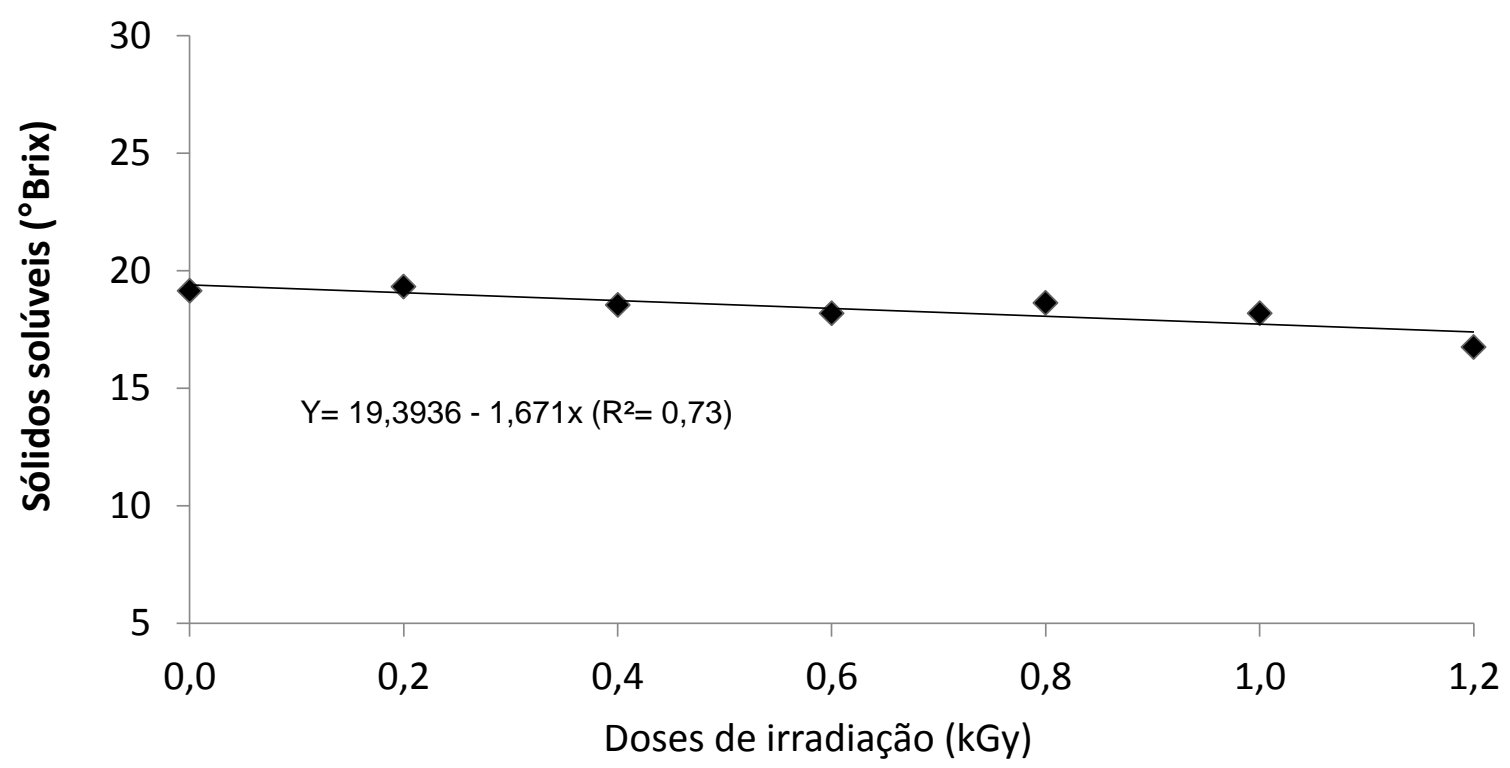

Os teores médios de sólidos solúveis encontrados nas atemoias em relação ao tempo de armazenamento, se mostraram crescentes no decorrer do tempo de 18 dias; iniciando os teores de sólidos solúveis com $13,67^{\circ}$ Brix no dia zero e chegando a $21,31{ }^{\circ}$ Brix no $18^{\circ}$ dia de armazenamento, dados apresentados na (Figura 3). Estas afirmações possibilitam a interpretação de que, por ser a atemoia uma fruta climatéria, o processo de amadurecimento ocorreu gradativamente durante 0 armazenamento; demonstrando que a irradiação não interferiu no processo bioquímico da respiração. Os dados obtidos neste experimento corroboram com Sousa (2013), o qual estudando atemoias cv. 'Gefner' em diferentes estádios de maturação, observou concentrações de sólidos solúveis em $20,68^{\circ}$ Brix em frutos semi maduros e $25,95^{\circ}$ Brix para frutos maduros. Estes dados divergem de Silva (2011) que estudando a qualidade de atemoias cv. 'Gefner' colhidos em dois estádios de maturação, obteve concentração de sólidos solúveis de $29,7^{\circ}$ Brix para frutos “de vez' e 31,25 ${ }^{\circ}$ Brix para frutos maduros, valores $71,7 \%$ e $68,16 \%$ maiores do que os encontrados neste experimento, para o maior teor de sólidos solúveis encontrado em atemoia cv. 'Thompson' aos 18 dias de armazenamento. 
Figura 3. Teores médios de sólidos solúveis ('Brix) em atemoia cv. 'Thompson' em função do período de armazenamento, acondicionadas em bandejas de poliestireno expandido, policloreto de vinila e armazenadas a $15 \pm 0,2 \circ \mathrm{C}$ e $90 \pm 2 \%$ de UR por 18 dias. Botucatu, SP.

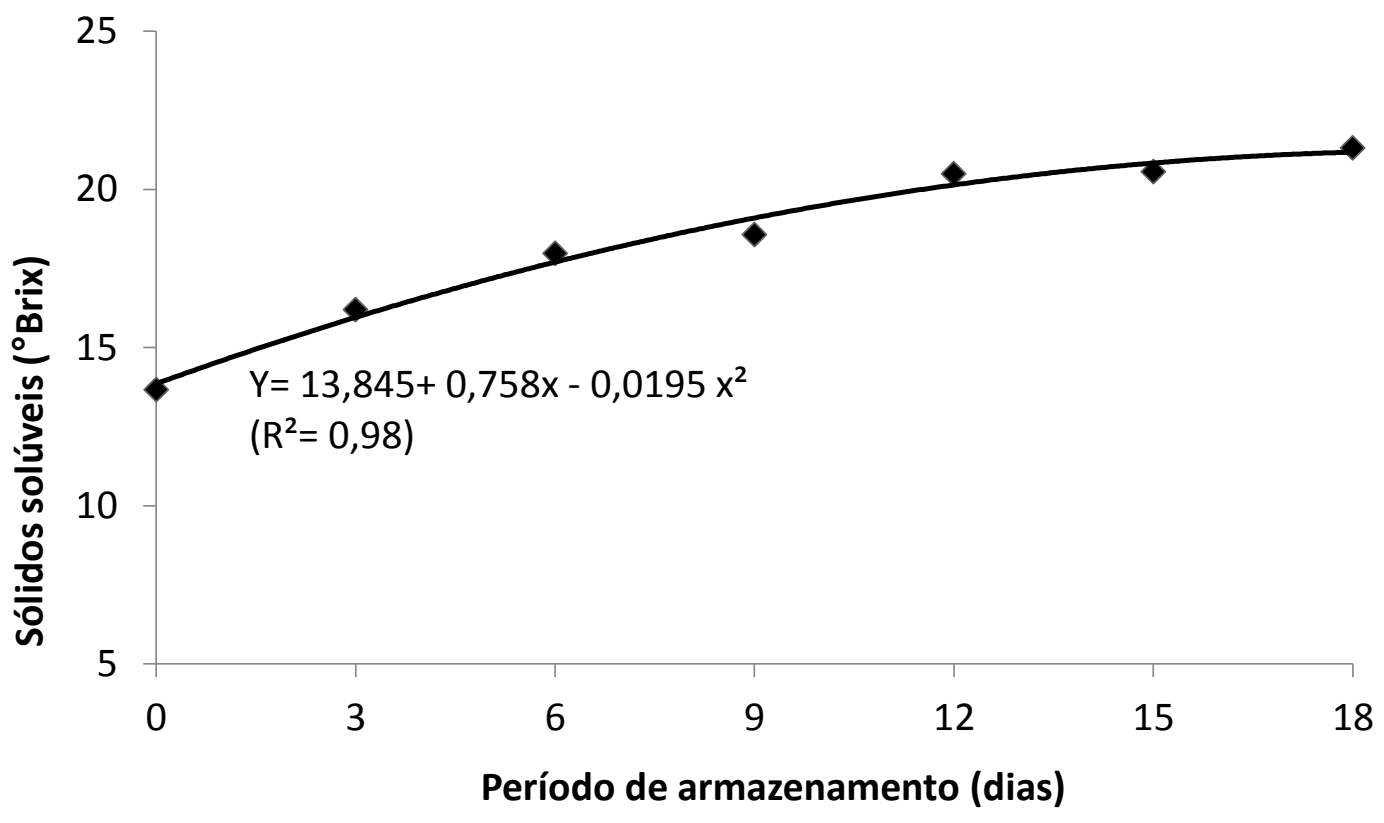

\section{Potencial hidrogeniônico $(\mathrm{pH})$ em atemoia irradiada}

O estudo da influência da radiação gama em atemoia cv "Thompson' para valores de $\mathrm{pH}$ demonstraram através dos dados obtidos na Tabela 1, a caracterização não significativa das doses de irradiação gama e a não interação destas com o período de armazenamento; estas informações possibilitam a interpretação de que o uso da irradiação ionizante com raios gama não interferiu nos valores de $\mathrm{pH}$ o qual tem relevância no processo de amadurecimento das frutas, pois o seu aumento aliado a uma diminuição da acidez titulável caracterizam indicativo de amadurecimento da fruta, sejam elas de climatérias ou não climatérias (CHITARRA; CHITARRA, 2005).

Tabela 1. Valores de pH em função das doses de irradiação (kGy) em atemoia cv. 'Thompson' acondicionadas em bandejas de poliestireno expandido e policloreto de vinila e armazenadas em $15 \pm 0,2^{\circ} \mathrm{C}$ e $90 \pm 2 \%$ de UR por 18 dias. Botucatu-SP.

\begin{tabular}{|c|c|c|c|c|c|c|c|c|}
\hline \multirow{2}{*}{ Doses } & \multicolumn{7}{|c|}{ Período de armazenamento (dias) } & \multirow{2}{*}{ Média } \\
\hline & 0 & 3 & 6 & 9 & 12 & 15 & 18 & \\
\hline Controle* & 6,06 & 5,83 & 5,75 & 5,91 & 5,68 & 5,53 & 5,83 & 5,80 \\
\hline $0,2 k G y$ & 6,06 & 5,98 & 6,08 & 5,68 & 5,81 & 5,51 & 5,81 & 5,85 \\
\hline $0,4 k G y$ & 6,06 & 6,16 & 5,94 & 5,80 & 5,62 & 5,52 & 5,78 & 5,84 \\
\hline $0,6 \mathrm{kGy}$ & 6,06 & 6,28 & 5,86 & 5,87 & 5,95 & 5,65 & 5,81 & 5,93 \\
\hline $0,8 \mathrm{kGy}$ & 6,06 & 5,97 & 5,90 & 5,89 & 5,71 & 5,63 & 5,85 & 5,86 \\
\hline 1,0kGy & 6,06 & 6,23 & 5,98 & 5,75 & 5,73 & 5,60 & 5,86 & 5,89 \\
\hline $1,2 \mathrm{kGy}$ & 6,06 & 6,25 & 5,84 & 5,74 & 5,85 & 5,85 & 5,68 & 5,89 \\
\hline C.V. (\%) & 3,2 & & & & & & & \\
\hline
\end{tabular}


A Figura 4 demonstrou os resultados obtidos para os valores de $\mathrm{pH}$ no decorrer do armazenamento das atemoias, demonstrando variação de 6,06 no dia zero até 5,8 no $18^{\circ}$ dia, o que representa uma diminuição percentual de 4,97\%. A influência do $\mathrm{pH}$ na bioquímica das frutas está relacionada ao amadurecimento do fruto, o qual coincide com aumento deste e redução da acidez titulável (CHITARRA; CHITARRA, 2005). Esta afirmação corrobora com Cardello e Cardello (1998), que avaliaram o amadurecimento de manga cv. 'Haden' em comparação com a variação do $\mathrm{pH}$ durante 14 dias, e neste período verificaram que ocorreu diminuição de $\mathrm{pH}$ e aumento de acidez titulável. Este fato pode ser explicado por Oh et al. (2006) que relata a influência da irradiação no $\mathrm{pH}$ de maneira que a mesma pode diminuir ou aumentar com a dose da irradiação aplicada, em virtude de sua interação com as moléculas de sacarose, glicose e frutose fragmentando estas para a formação de ácidos. Os dados obtidos com atemoia neste experimento corroboram com Souza (2013) que avaliando parâmetros químicos da atemoia cv. 'Gefner' observou valor de $\mathrm{pH}$ igual a 5,36 no fruto completamente maduro; adicionalmente Silva (2011), observou em atemoia cv. 'Gefner' plenamente madura um valor de $\mathrm{pH}$ igual a 5,58; esse dado corrobora com Torres (2008), o qual avaliando o póscolheita da atemoia cv. 'Thompson', encontrou valores de $\mathrm{pH}$ iguais a 5,5 nos frutos maduros armazenados nas condições de temperatura ambiente $\left(22-25^{\circ} \mathrm{C}\right.$ e $60+10 \%$ de UR) e a $15+1^{\circ} \mathrm{C}$ e $70-75 \%$ de UR.

Figura 4. Valores de pH em atemoia cv. 'Thompson' em função das doses de irradiação (kGy) acondicionadas em bandejas de poliestireno expandido, policloreto de vinila e armazenadas a $15 \pm 0,2{ }^{\circ} \mathrm{C}$ e $90 \pm 2 \%$ de UR por 18 dias. Botucatu, SP.

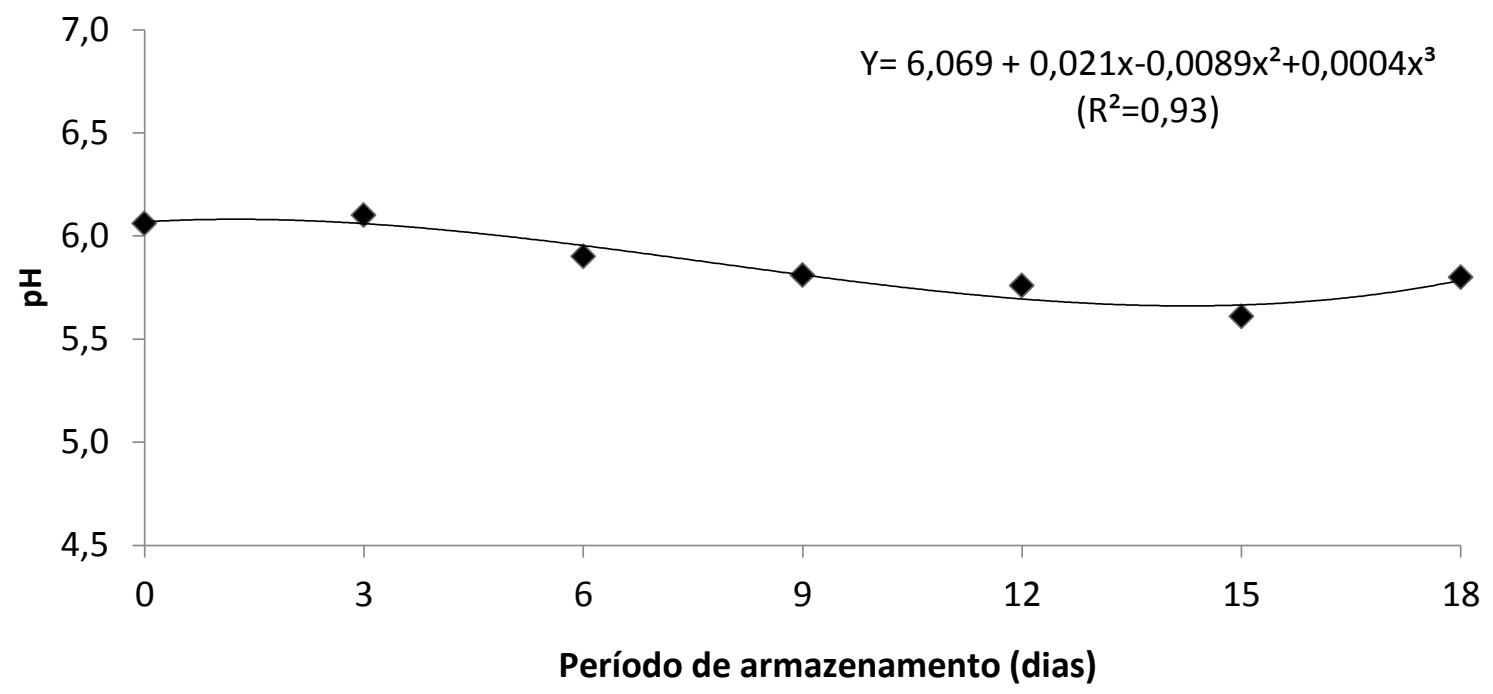

\section{Acidez titulável (AT) em atemoia irradiada}

Os dados obtidos com a acidez titulável (AT), possibilita observar que houve diferença estatística na dose $1 \mathrm{kGy}$ durante o período de armazenamento. Os teores de AT apresentaram aumento até $09^{\circ}$ dia $(0,277 \mathrm{~g}$ de ácido cítrico 100 $\left.\mathrm{g}^{-1}\right)$, e após esse período houve redução dos resultados, sendo que no $18^{\circ}$ dia obteve-se $\left(0,093 \mathrm{~g}\right.$ de ácido cítrico $\left.100 \mathrm{~g}^{-1}\right)$. Os demais tratamentos não apresentaram diferença estatística durante o período de armazenamento, conforme (Figura 5).
Essa observação possibilita interpretar que o tratamento a $1,0 \mathrm{kGy}$ foi o tratamento que atuou no controle do amadurecimento da atemoia cv. 'Thompson', até $09^{\circ} \mathrm{dia}$, possibilitando assim maior durabilidade do fruto em pós-colheita essa afirmação é esclarecida por Chitarra e Chitarra (2005), que relatam a importância da manutenção de valores altos da acidez titulável, pois no processo de amadurecimento do fruto, esta tende a diminuir. 
Figura 5. Teores de acidez titulável ( $\mathrm{g}$ de ácido cítrico $100 \mathrm{~g}^{-1}$ ) em função das doses de Irradiação (kGy) em atemoia cv. 'Thompson' acondicionadas em bandejas de poliestireno expandido, policloreto de vinila e armazenadas a $15 \pm 0,2 \circ \mathrm{C}$ e $90 \pm 2 \%$ de UR por 18 dias. Botucatu, SP.

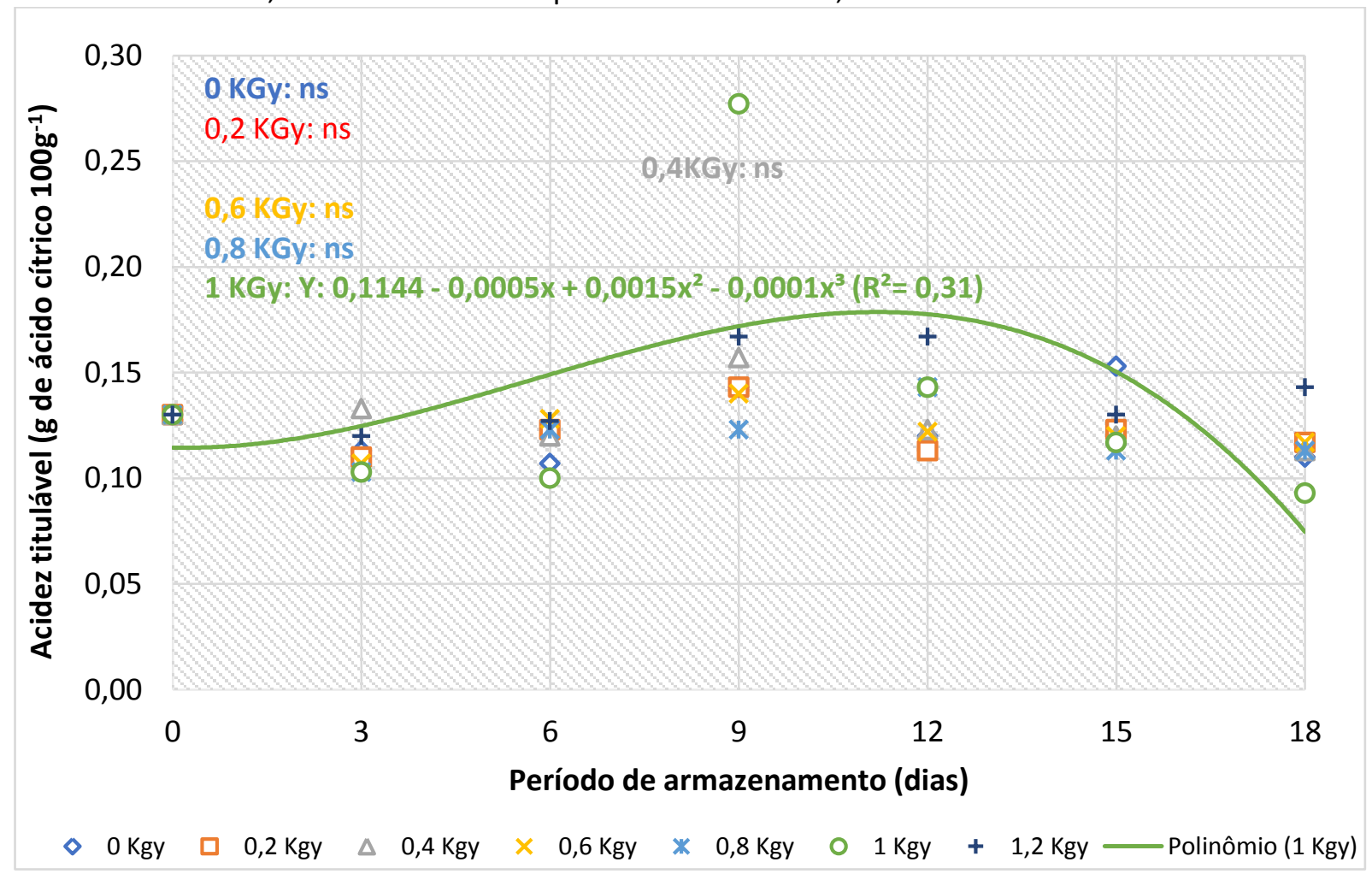

Dados encontrados por Mendonça (2016), estudando a influência da irradiação ionizante na acidez titulável de caqui cv. 'Kioto', obteve redução desta até os 21 dias, já os dados observados por Calore (2003) demonstraram que os maiores índices de ácidez titulável em pêssegos cv. 'Buiuti' irradiados, foram encontrados em doses específicas de 0,2kGy e $0,4 k G y$ permitindo a estes uma conservação por 14 dias.

\section{Perda de massa (PM) em atemoia irradiada}

Os dados de análise para a perda de massa (\%), estão elucidados na Figura 6. Para a perda de massa (PM) houve diferença entre as médias dos tratamentos quanto as doses de irradiação; sendo que a menor PM foi observada nos frutos tratados com $0,4 \mathrm{kGy}(0,619 \%)$ e a maior perda no tratamento com $1 \mathrm{kGy}(1,12 \%)$, estes dados possibilitam a interpretação de que doses altas de irradiação não favorecem o controle de perda de massa nas atemoias cv. 'Thompson'. A esta informação pode-se complementar a afirmação de que a perda de massa das frutas está associada principalmente à perda de água ocasionada tanto pela transpiração como pela respiração das frutas durante $O$ processo de amadurecimento (CHITARRA; CHITARRA, 2005).

Trabalho de pesquisa desenvolvido por Calore (2003), o qual estudou a conservação de pêssegos cv. 'Buiuti' observou que a menor perda de massa fresca foi obtida com a dose de 0,1kGy. 
Figura 6. Valores médios da perda de massa (\%) em função das doses de irradiação (kGy) em atemoia cv. 'Thompson' acondicionadas em bandejas de poliestireno expandido, policloreto de vinila e armazenadas a $15 \pm 0,2 \circ \mathrm{C}$ e $90 \pm 2 \%$ de UR por 18 dias. Botucatu, SP.

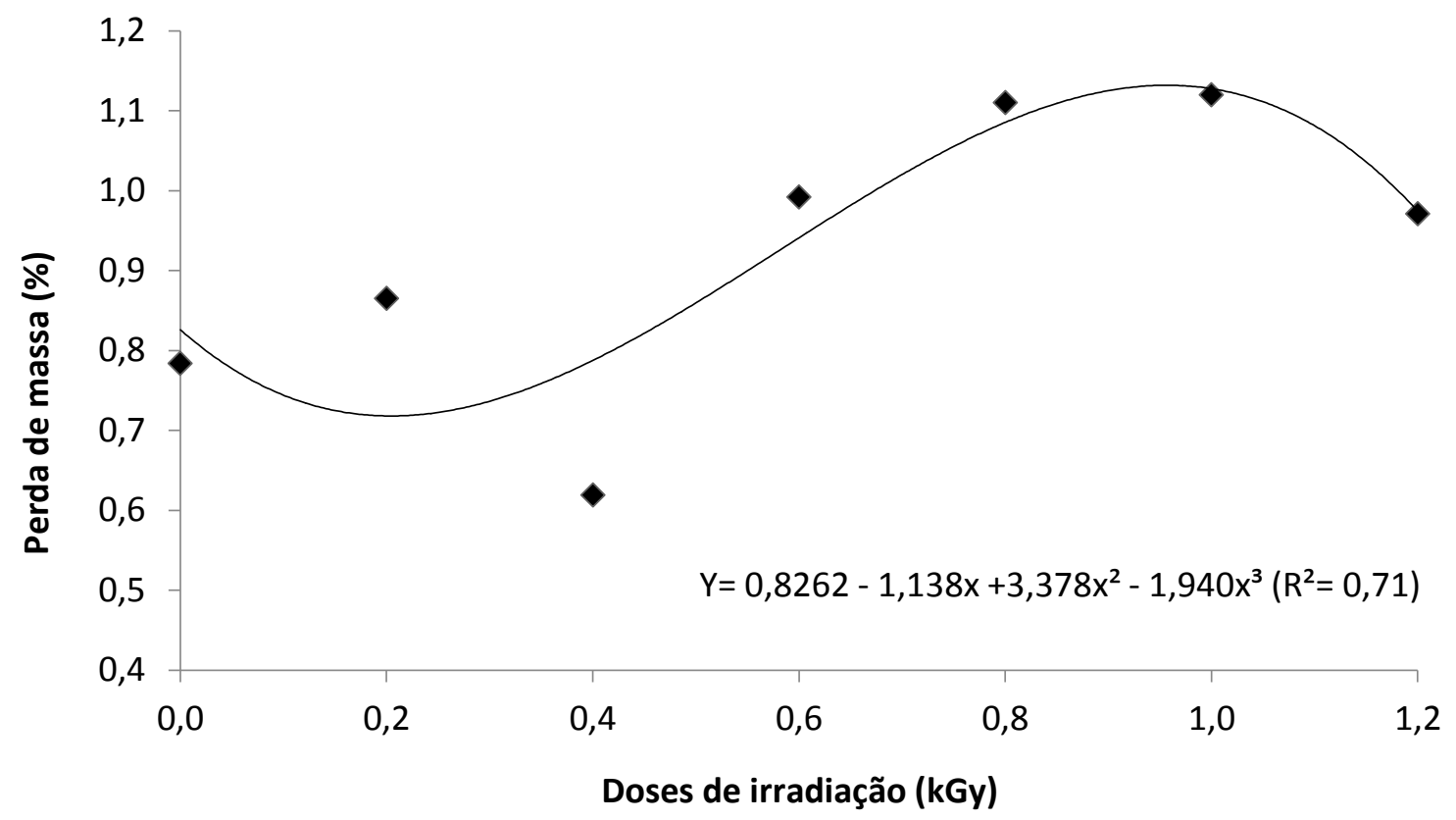

A perda de massa (\%) obtida nos frutos análise; verificou-se perdas entre $\circ 3^{\circ}$ e $\circ 18^{\circ}$ irradiados e sua relação entre doses e tempo de armazenamento, demonstraram perdas (Figura 7). constantes no decorrer de dezoito dias de

Figura 7. Perda de massa (\%) em atemoia cv. 'Thompson', em decorrência do período de armazenamento e das doses de irradiação (kGy), acondicionadas em bandejas de expandido, policloreto de vinila e armazenadas a $15 \pm 0,2 \circ \mathrm{C}$ e $90 \pm 2 \%$ de UR poliestireno 18 dias. Botucatu, SP.

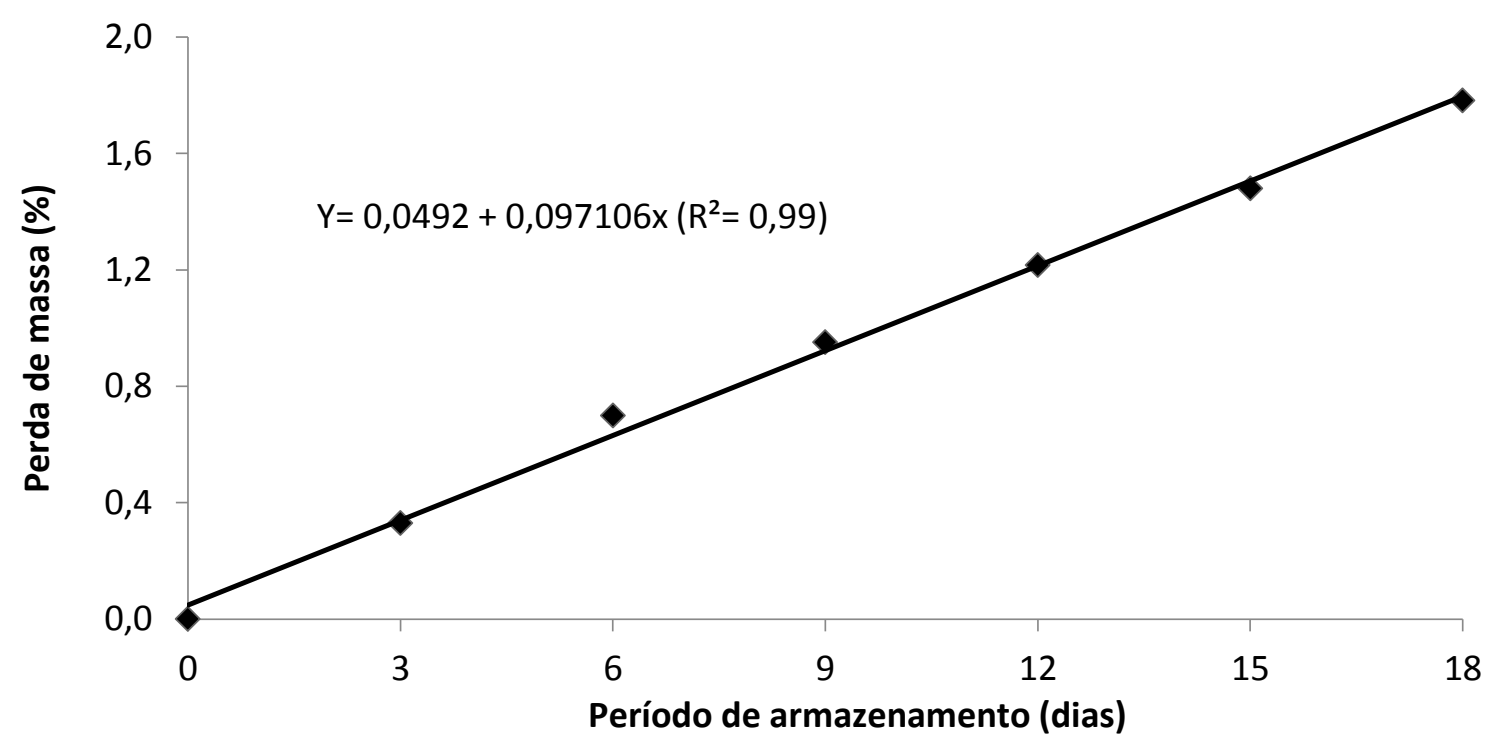

A perda de massa em frutas ocorre em função da perda de água e soluto por transpiração e respiração respectivamente; Chitarra e Chitarra (2005) cita que $3 \%$ de perda de massa pode ocasionar diminuição na qualidade das frutas, este dado corrobora com Torres (2008), o qual observou $12 \%$ de perda de massa no $9^{\circ}$ dia de análise em atemoia cv. 
'Thompson' armazenadas a $15 \pm 1$ 으 $\mathrm{C}$ e $70-75 \%$ de UR; sem controle de embalagem. Estes dados enfatizam a importância da avaliação da perda de massa como indicativo de análise para avaliação de maior vida de prateleira de um fruto, a qual tem relação inversamente proporcional as perdas em pós-colheita e diretamente proporcional ao maior ganho financeiro por parte do produtor.

\section{Ácido ascórbico em atemoia irradiada}

$\mathrm{Na}$ análise apresentada na Tabela 2, os teores de ácido ascórbico demonstram que as médias dos tratamentos e a interação destes com
- período de armazenamento nas atemoias irradiadas não foram significativas entre si a $5 \%$ de probabilidade, pelo teste de Tukey; o que possibilita a interpretação de que o uso da irradiação ionizante não influenciou os teores de ácido ascórbico (um antioxidante) durante o amadurecimento natural da atemoia. Sendo relevante salientar que não fora encontrado na literatura trabalhos os quais demonstrassem relação entre o percentual de ácido ascórbico e amadurecimento em atemoias.

Tabela 2. Teores de ácido ascórbico ( $\mathrm{mg}$ de ácido ascórbico $100 \mathrm{~g}^{-1}$ ) em atemoia cv. 'Thompson' em função das doses de irradiação ( $k G y$ ) acondicionadas em bandejas de poliestireno expandido e policloreto de vinila e armazenadas em $15 \pm 0,2$ ㅇ C e $90 \pm 2 \%$ de UR por 18 dias. Botucatu, SP.

As médias do tratamento e interação não foram significativas entre si a $5 \%$ de probabilidade, pelo teste de Tukey. $(*)$ $\mathrm{O}$ tratamento controle caracteriza-se por frutos lavados em água corrente e posteriormente secos à temperatura ambiente.

Os teores de ácido ascórbico encontrados no decorrer do período de armazenamento nas atemoias estão descritos na Figura 8, a qual demonstraram diminuição crescente no decorrer dos 18 dias de armazenamento. Durante o amadurecimento a fruta apresenta diminuição nos índices de ácido ascórbico, sendo que Chitarra e Chitarra (2005), esclarece que o referido ácido possui ação de retardo no processo de amadurecimento em função de atuar na desintoxicação do peróxido de hidrogênio. A vitamina $C$ atua como cofator enzimático, participando dos processos de óxido-redução, aumentando a absorção de ferro e a inativação de radicais livres (Levine et al., 2011)

A influência da radiação ionizante na mudança química da fruta, quanto a possível perda de sequestradores de radicais livres, a exemplo do ácido ascórbico (Chitarra e Chitarra, 2005). Ventura et al. (2010) esclarece que o ácido ascórbico em solução é completamente instável à radiação, mas nas frutas e vegetais parecem totalmente estáveis em tratamentos com doses baixas. Koblitz (2008) caracteriza que o produto oxidado da vitamina $\mathrm{C}$, o ácido $\mathrm{L}$. desidroascórbico, tem a mesma atividade 
biológica, mas é pouco estável, sendo sua formação praticamente instantânea em pH alcalino, rápida ao redor da neutralidade e lenta em condições ácidas, essas afirmações podem explicar a não significância das médias, em função da variação de $\mathrm{pH}$ encontrada neste experimento.

Figura 8. Teores de ácido ascórbico ( $m g$ de ácido ascórbico $100 \mathrm{~g}^{-1}$ ) em atemoia cv. 'Thompson' em função das doses de irradiação (kGy) acondicionadas em bandejas de poliestireno expandido, policloreto de vinila e armazenadas a $15 \pm 0,2 \circ \mathrm{C}$ e $90 \pm 2 \%$ de UR por 18 dias. Botucatu, SP.

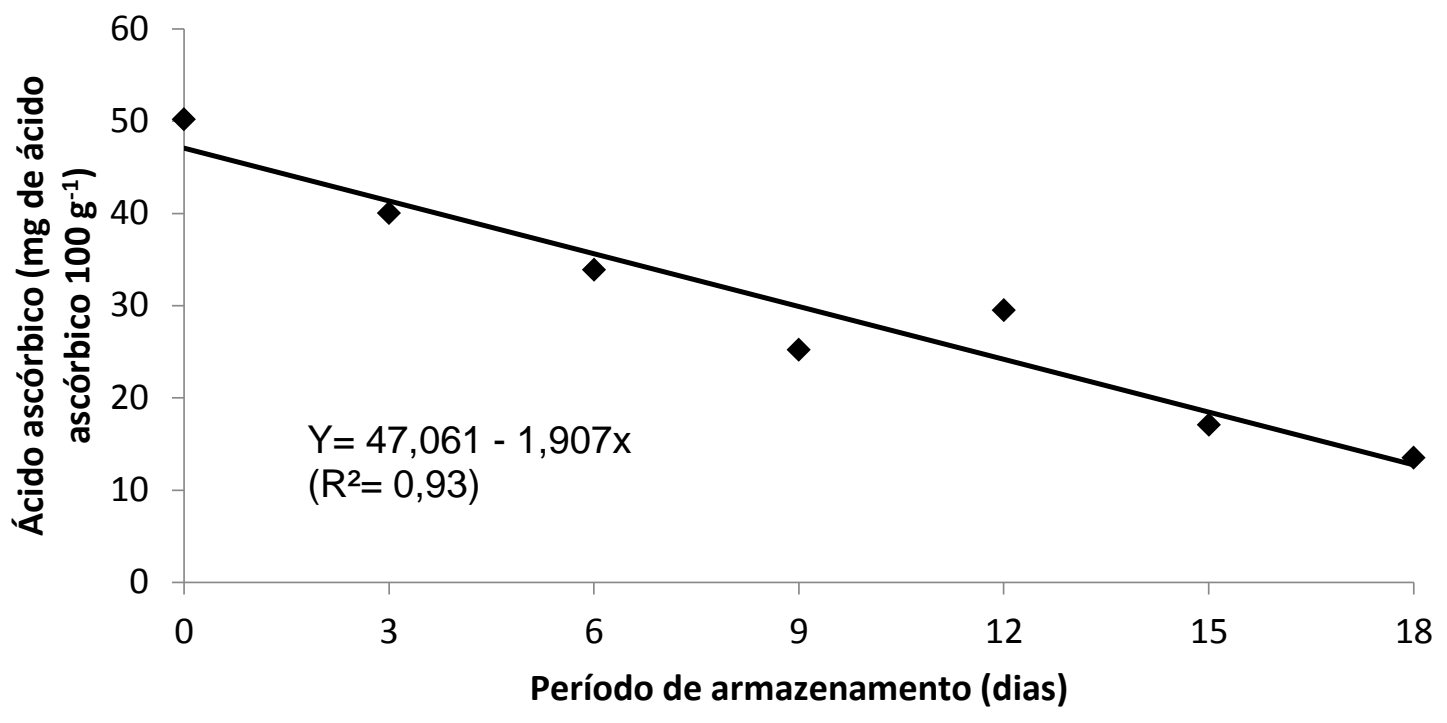

\section{Açúcar redutor em atemoia irradiada}

O teor de açúcar redutor encontrado no experimento com irradiação ionizante nas atemoias demonstraram através da Figura 9, que o tratamento com dose de $0,8 \mathrm{kGy}$ apresentou no dia zero $4,18 \%$ de açúcar redutor e no $18^{\circ}$ dia de armazenamento o índice foi de 9,16\%. 0 tratamento com 1,2kGy apresentou os menores índices de açúcar redutor no mesmo período. A importância dos açucares redutores no processo de amadurecimento pode ser explicado por Ribeiro e Seravalli (2007), que caracteriza ser a hidrólise da sacarose influenciada pelo $\mathrm{pH}$ (francamente ácido), temperatura (baixa temperatura) e tempo; a não hidrólise dos açúcares redutores mantem os frutos como não maduros; os mesmos autores relatam que a maioria dos dissacarídeos (glicose + frutose $=$ sacarose), encontrados em alimentos são redutores, exceção feita a sacarose, a qual é sensível a hidrólise ácida, e sob ação desta, é posteriormente transformada em D-glicose e Dfrutose, que é indicador de amadurecimento. Os dados obtidos neste experimento corroboram com Lundgren (2017) que obteve aumento dos valores de açúcares redutores no período de dezoito dias de armazenamento, para atemoias cv. 'Thompson' tratadas com diferentes doses de 1-MCP, mas com índices superiores ao deste experimento, ou seja, no dia zero $5 \%$ e no dia dezoito $20,84 \%$. 
Figura 9. Teores de açúcar redutor (\%) em atemoia cv. 'Thompson' em função das doses de irradiação (kGy), acondicionadas em bandejas de poliestireno expandido, policloreto de vinila e armazenadas a $15 \pm$ $0,2 \circ \mathrm{C}$ e $90 \pm 2 \%$ de UR por 18 dias. Botucatu SP

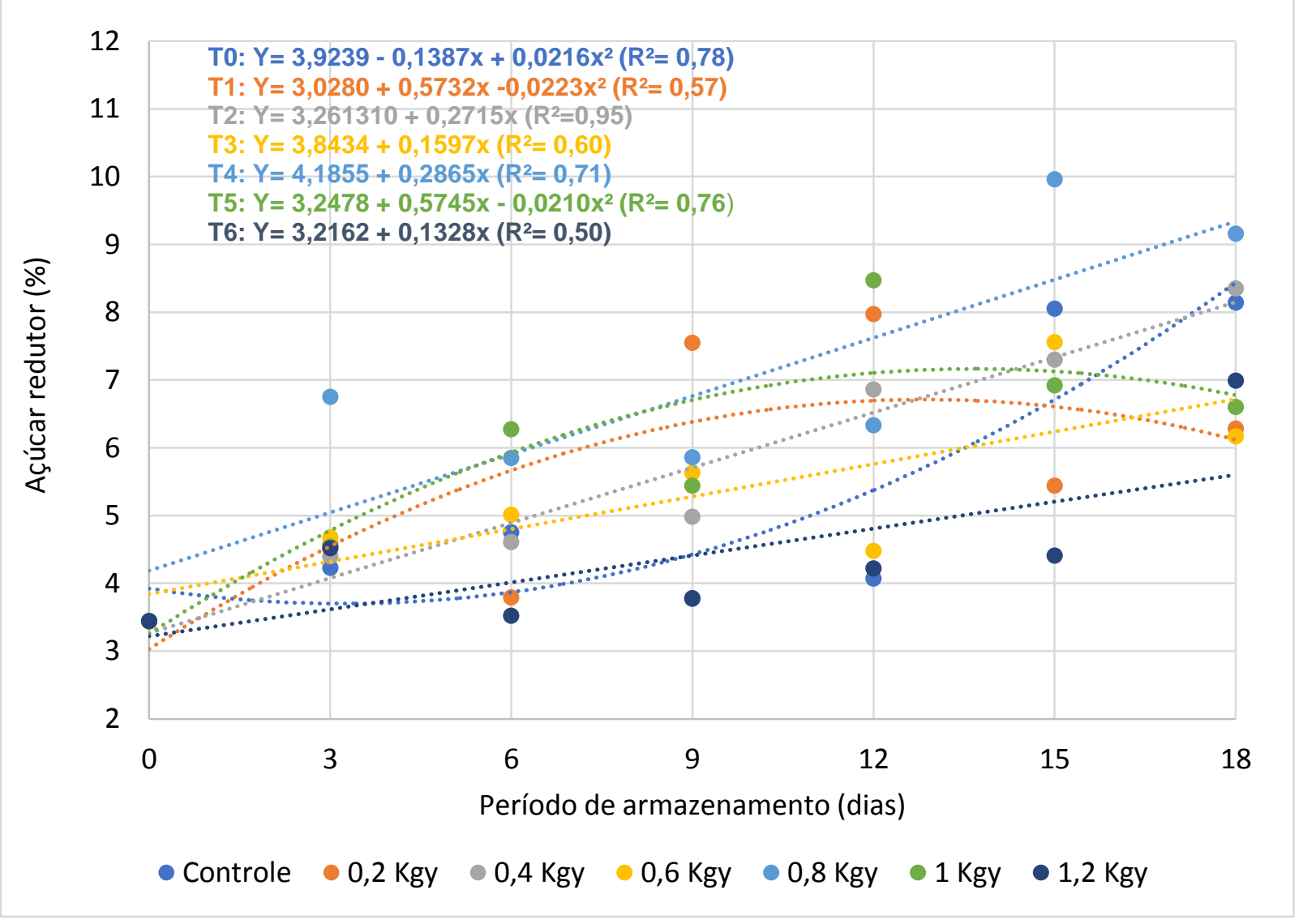

\section{Conclusão}

Os resultados obtidos neste experimento possibilitam concluir que:

- A dose de $1,2 \mathrm{kGy}$ foi a única que manteve a taxa respiratória reduzida até $0 \quad 60$ dia de armazenamento.

- Para os demais itens analisados os tratamentos com irradiação ionizante não demonstraram interferência no aumento de vida pós-colheita da atemoia cv 'Thompson'.

\section{Referências}

AOAC. Official methods of analysis of the Association of Oficial Analitycal Chemistry International. 21th ed. Washington, 2019.

BONAVENTURE, L. A cultura da cherimóia e de seu híbrido, a atemóia. São Paulo: Nobel, 1999.

CALBO, A.G. (ed.). Respiração de frutas e hortaliças. Brasília: Embrapa, 2007. 10 p.

IAL. Normas Analíticas do Instituto Adolfo Lutz Métodos Químicos e Físicos para Análise de Alimentos. 4. Ed. Brasília: 2008. 1018p.

CALORE, L.; VIEITES, R.L. Conservação de pêssegos 'Biuti' por irradiação. Ciência Tecnologia de Alimentos, v.2, n. 23, p. 53-57, dez. 2003. https://doi.org/10.1590/s0101$\underline{20612003000400010}$

CARDELLO, M.H.A. B.; CARDELLO, L. Teor de vitamina $c$, atividade de ascorbato oxidase e perfil sensorial de manga (Mangífera índica L.) var. Haden, durante o amadurecimento. Ciência e Tecnologia de Alimentos, Campinas, v. 18, n. 2, p.213-227, jul. 1998. https://doi.org/10.1590/S010120611998000200013

CHITARRA, M. I. F.; CHITARRA, A. B. Pós-colheita de frutos e hortaliças- Fisiologia e Manuseio. Lavras: UFLA, 2005. 
CONAB. Programa brasileiro de modernização do mercado hortigranjeiro - PROHORT. Disponível em: http://dw.prohort.conab.gov.br/pentaho/Prohor t. Acesso em: 27 mar. 2017.

EVANGELISTA, J. Tecnologia de alimentos. 2. ed. São Paulo: Atheneu, 2008. 652 p.

FELLOWS, P.J. Tecnologia do processamento de alimentos: princípios e prática. 2. ed. Porto Alegre: Artmed, 2006. 602 p.

FERREIRA, D. F. Sisvar - Sistema de Análise de Variância. Versão 5. 3. Lavras: UFLA, 2010.

GAVA, A. J.; SILVA, C. A. B.; FRIAS, J. R. G. Tecnologia de alimentos: princípios e aplicações. São Paulo: Nobel, 2009. 511 p.

JUDD, W. S. et al. Sistemática vegetal: um enfoque filogenético. 3. ed. Porto Alegre: Artmed, 2009.

KOBLITZ, M. G. B. Bioquímica dos alimentos. Rio de Janeiro: Guanabara Koogan, 2008. 242 p.

LEVINE, M.; PADAYATTY, S.J.; ESPEY, M.G. Vitamin C: a concentration-function approach yields pharmacology and therapeutic discoveries - a review-. American Society for Nutrition, v.2, n.2, p.78-88, 2011.

https://doi.org/10.3945/an.110.000109

LUNDGREN, G. A. Conservação de atemoia submetida a 1-metilciclopropeno. 2017. 79 f. Dissertação (Mestrado) - Curso de Engenharia Agronômica, Horticultura, Faculdade de Ciências Agronômicas da Unesp - Campus de Botucatu, Botucatu, 2017.

MARTINELLI, G.; MORAES, M. A. Livro vermelho da flora do Brasil. Rio de Janeiro: Cncflora, 2013. Disponível em: file:///C:/Users/ghmv/Downloads/LivroVermelho (2).pdf. Acesso em: 05 jun. 2017.

MENDONÇA, V. Z. Métodos Físicos na Conservação de Caqui cv. Kioto in natura e minimamente processado. 2016. 125 f. Tese (Doutorado) - Curso de Agronomia, Energia na Agricultura, Universidade Estadual Paulista "Júlio de Mesquita Filho" Faculdade de Ciências
Agronômicas Campus de Botucatu, Botucatu, 2016.

MORTON, J. Fruits of warm climates. Miami:

Creative Resource, 1987. p.72-75.

NEVES, L.C.; MANZIONE, R.L.; VIEITES, R. L. Radiação gama na conservação pós-colheita da nectarina (Prunus persica variedade. 'Nucipersica') frigoconservada. Revista Brasileira de Fruticultura, Jaboticabal, v. 24, n. 3, p. 676679, dezembro 2009. https://doi.org/10.1590/S010029452002000300026

O'BEIRNE, D. Irradiation of fruits and vegetables: applications and issues. Professional Horticulture, Oxford, v. 3, n. 1, p. 12-19, 1989.

OH, S. H.; LEE, Y. S.; KIM, J. H.; KIM, J. H.; LEE, J. W.; KIM, M. R.; YOOK, H, S.; BYUN, M. W. Effects of $\mathrm{pH}$ on non-enzymatic browning reaction during $y$-irradiação processing using sugar and sugarglycine solution. Food Chemistry, v.94, p-420427, Amsterdan, 2006. https://doi.org/10.1016/j.foodchem.2004.11.034

RIBEIRO, E. P.; SERAVALLI, E. A. G. Química de alimentos. 2. ed. São Paulo: Edgard Blücher, 2007.

SILVA, A.V.C.; MUNIZ, E.N. Qualidade de atemóia colhida em dois estádios de maturação. Revista Caatinga, Mossoró, v. 24, n. 4, p. 9-13, 2011.

SOUSA, F. C.; SOUZA, E. P.; CRUZ, C. S. A; GOMES, J. P.; ALMEIDA, F. A. C. Parâmetros físicos e físico-químicos da atemóia 'Gefner' em diferentes estádios de maturação. Revista Brasileira de Produtos Agroindustriais, Campina Grande, v. 15, n. 3, p. 329-324, 2013. https://doi.org/10.15871/15178595/rbpa.v15n4p329-334

TEZOTTO, J. U. V. et al. Radiação gama em produtos de origem vegetal. Revista Virtual de Química, Piracicaba, v. 7, n. 1, p. 267-277, nov. 2014.

TOKUNAGA, T. A cultura da atemóia. Campinas: CATI), 2000.

TORRES, L. M. A. R. Conservação pós-colheita de atemóia cv. 'Thompson'. 2008. $149 \mathrm{f}$. 
Dissertação (Mestrado) - Curso de Farmácia, Ciência dos Alimentos, Faculdade de Ciências Farmacêuticas da Universidade Estadual Paulista “Júlio de Mesquita Filho", Araraquara, 2008.

VENTURA, D. et al. Utlização da irradiação no tratamento de alimentos: processamento geral de alimentos - módulo II. Coimbra: Escola Superior Agrária de Coimbra, 2010. 31 p. Disponível em: http://www.esac.pt/noronha/pga/0910/trabalho _mod2/irradiacao_grupo4_t2_word.pdf. Acesso em: 31 out. 2017. 